\title{
Use of the \\ National Driver Register in the \\ U.S. Department of Energy Human Reliability Program
}

\section{O R I S E}

Center for Human Reliability Studies Oak Ridge Institute for Science and Education Operated by Oak Ridge Associated Universities

For the U.S. Department of Energy 
Oak Ridge Associated Universities (ORAU) is a university consortium leveraging the scientific strength of major research institutions to advance science and education by partnering with national laboratories, government agencies, and private industry. ORAU manages the Oak Ridge Institute for Science and Education for the U.S. Department of Energy.

The Oak Ridge Institute for Science and Education (ORISE) is a U.S. Department of Energy institute focusing on scientific initiatives to research health risks from occupational hazards, assess environmental cleanup, respond to radiation medical emergencies, support national security and emergency preparedness, and educate the next generation of scientists. ORISE is managed by Oak Ridge Associated Universities.

The Center for Human Reliability Studies (CHRS) provides a vehicle for achieving quality-oriented program support for DOE through research and analysis, technical guidance, and operational support in all areas of human reliability relating to occupational medicine, facility safety, personnel security, and the DOE Human Reliability Program. CHRS also conducts research on issues involving personnel reliability.

This document was produced under contract number DE-AC05-06OR23100 between the U.S. Department of Energy and Oak Ridge Associated Universities. 


\title{
Use of the National Driver Register in the U.S. Department of Energy Human Reliability Program
}

\author{
Prepared for \\ Office of Security Policy \\ Office of Health, Safety and Security \\ U. S. Department of Energy \\ Washington, D.C.
}

by

Phillip M. Kannan, J.D.

Center for Human Reliability Studies

Oak Ridge Institute for Science and Education

Oak Ridge, Tennessee

ORISE 07-0012

January 2007 



\section{Table of Contents}

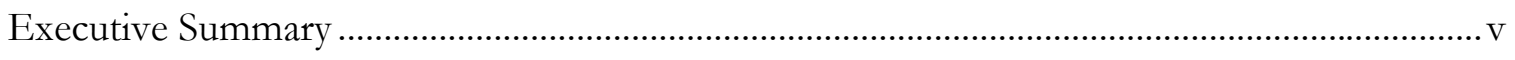

I. Introduction to the National Driver Register ..........................................................

II. Authority of DOE to Receive NDR Reports …............................................................. 2

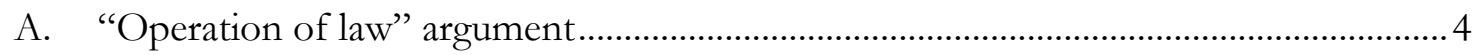

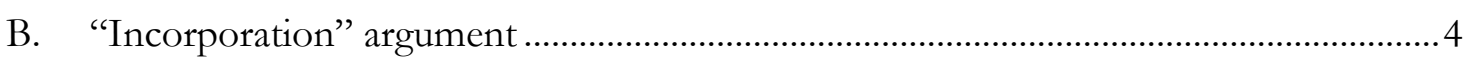

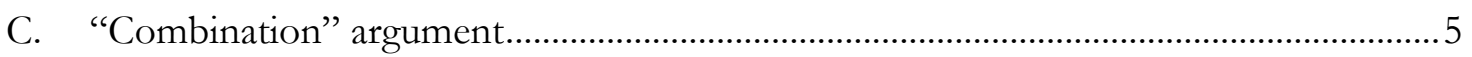

III. Using the NDR in the Access Authorization Program: A Brief Overview ................... 6

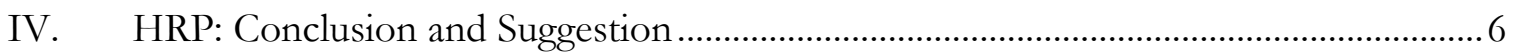




\section{Executive Summary}

The National Driver Register (NDR) is a complex information network established and maintained by the Secretary of the Department of Transportation (DOT) under the National Driver Register Act of 1982. This report analyzes the question of whether information from the NDR is available to officials making Human Reliability Program (HRP) certification and recertification decisions and to Department of Energy (DOE) personnel security specialists making access authorization determinations.

There are only ten categories of entities that are authorized to receive information from the NDR. Of particular interest in this report is category nine, which was added to the list on October 28, 2004:

(9) An individual who has or is seeking access to national security information for purposes of Executive Order No. 12968, or any successor Executive order, or an individual who is being investigated for Federal employment under authority of Executive Order No. 10450...

Executive Order No. 10450 is listed in the HRP regulation (10 CFR Part 712) as a source of legal authority; thus, the records of federal employees can be received under the HRP. Executive Order 12968, however, is not listed in that regulation. The report develops three arguments, each of which supports the conclusion that the NDR records of contractor employees can be received.

The first argument, called the operation of law argument, is based on the fact that Executive Order 12968 was issued in response to a statute that required the President to "establish procedures to govern access to classified information which shall be binding upon all departments, agencies, and offices of the executive branch of Government." The President's response was Executive Order 12968 which, as required by Congress, applies to all federal departments and agencies. This includes DOE. Thus, by operation of law, all of the security programs of DOE related to access to classified information, including the HRP, are implementations of Executive Order 12968.

The second argument, called the incorporation argument, is based on the fact that the HRP regulation lists Executive Order 10865 as a source of authority. Executive Order 12968 specifically includes a provision regarding Executive Order 10865. By including this 
reference to Executive Order 10865, Executive Order 12968 has incorporated it. Thus, the reference to Executive Order 12968 in the National Driver Register Act of 1982 as a sufficient basis for an agency receiving information from the NDR is satisfied by the listing of Executive Order 10865 as a source of authority in the HRP regulation.

The third argument, called the combination argument, is based on the combination of the first two. First, Congress required the President to issue an executive order governing access to classified information by all persons. Second, the President complied by issuing Executive Order 12968, which specifically acknowledged Executive Order 10865.

The report briefly considers whether the DOE access authorization program can receive information from the NDR. It notes that the DOE access authorization regulations do not list Executive Order 12968 as a source of authority. The same three arguments given for the HRP authority apply for the DOE access authorization program. Again, a regulation explicitly identifying Executive Order 12968 as a source of authority for the DOE access authorization program can be issued by DOE, which would remove any question regarding access to the NDR records.

The report concludes that, to remove the risk that these arguments might not be accepted by a court, DOE can issue a regulation explicitly identifying Executive Order 12968 as a source of authority for the HRP. 


\section{Introduction to the National Driver Register}

The National Driver Register (NDR) is a complex information network established and maintained by the Secretary of the Department of Transportation (DOT) under the National Driver Register Act of 1982. ${ }^{1}$ This report analyzes the question of whether information from the NDR is available to officials making Human Reliability Program (HRP) certification and recertification decisions and to Department of Energy (DOE) personnel security specialists making access authorization determinations.

The purpose of the NDR is to "assist chief driver licensing officials of participating states in exchanging information about motor vehicle driving records of individuals." ${ }^{2}$ States can elect to participate in this exchange process $;^{3}$ all fifty states and the District of Columbia have chosen to do so. ${ }^{4}$

Under this law, DOT maintains a database containing information submitted by states. The law requires the following:

As soon as practicable, the chief driver licensing official of each participating State shall submit to the Secretary of Transportation a report containing the information specified by subsection (b) of this section for each individual--

(1) who is denied a motor vehicle operator's license by that State for cause;

(2) whose motor vehicle operator's license is revoked, suspended, or canceled by that State for cause; or

(3) who is convicted under the laws of that State of any of the following motor vehicle-related offenses or comparable offenses:

(A) operating a motor vehicle while under the influence of, or impaired by, alcohol or a controlled substance.

(B) a traffic violation arising in connection with a fatal traffic accident, reckless driving, or racing on the highways.

(C) failing to give aid or provide identification when involved in an accident resulting in death or personal injury.

(D) perjury or knowingly making a false affidavit or statement to officials about activities governed by a law or regulation on the operation of a motor vehicle. ${ }^{5}$

\footnotetext{
149 U.S.C. 33 (2006).

249 U.S.C. $\$ 30302($ a) (2006).

349 U.S.C. $\$ 30303$ (a) (2006).

471 Fed. Reg. 19823, 19824 (April 18, 2006) stating, “... all 50 States and the District of Columbia currently participate in the NDR PDPS (Problem Driver Pointer System).”

549 U.S.C. \$30304(b) (2006).
} 
To make this data efficiently usable, DOT has created a device known as the Problem Driver Pointer System (PDPS). When a request for information is received from a valid requestor about a specific person, the DOT matches his or her identity against the names in the PDPS. If a match is found, the PDPS record points to the "State where the substantive adverse records about the driver can be obtained."

Disclosure of the information in the database developed by the DOT from these submissions is limited by statute; a disclosure can be made only to specific categories of requestors. ${ }^{7}$ It should be noted that there are two ways for a federal agency, which has been authorized by the National Driver Register Act to receive information about a specific individual from the NDR, to actually obtain it. One is for the federal agency to have the individual complete and sign a request form. The federal agency then submits it to the chief driver licensing official of a state. ${ }^{8}$ The other way is much more direct; it allows the agency to submit the request directly to the DOT. This direct method is recognized as follows by the DOT regulations:

The NDR statute allows the head of a Federal department or agency authorized to receive information regarding an individual from the NDR to request and receive such information from the Secretary of Transportation. 49 U.S.C. 30305(b)(11). This provision, by its operation, affords direct access to the NDR to identified Federal departments and agencies (through NHTSA) without the need to submit an inquiry to a State chief driver licensing official. In practice, virtually all Federal departments or agencies with specific access provisions have submitted inquiries directly to NHTSA. ${ }^{9}$

\section{Authority of DOE to Receive NDR Reports}

As noted above, only the entities identified in the regulation are authorized to receive information from the NDR. Of particular interest in this report is category nine, which was added to the list on October 28, 2004. ${ }^{10}$ This provision states:

(9) An individual who has or is seeking access to national security information for purposes of Executive Order No. 12968, or any successor Executive order, or an

\footnotetext{
671 Fed. Reg. 19823 (April 18, 2006).

749 U.S.C. $\$ 30305(b)$ (2006).

871 Fed. Reg. 19823, 19824 (April 18, 2006).

${ }^{9}$ Id. NHTSA is the National Highway Traffic Safety Administration.

10 Public Law 108-375, Section 1061, codified at 49 U.S.C. \$30305(b)(9) (2006).
} 
individual who is being investigated for Federal employment under authority of Executive Order No. 10450, or any successor Executive order, may request the chief driver licensing official of a State to provide information about the individual pursuant to subsection (a) of this section to a Federal department or agency that is authorized to investigate the individual for the purpose of assisting in the determination of the eligibility of the individual for access to national security information or for Federal employment in a position requiring access to national security information. A Federal department or agency that receives information about an individual under the preceding sentence may use such information only for purposes of the authorized investigation and only in accordance with applicable law. ${ }^{11}$

The HRP was established by regulations promulgated on January 23, 2004 and codified at 10 CFR Part 712. ${ }^{12}$ As codified, the authority for the HRP is as follows:

AUTHORITY NOTE APPLICABLE TO ENTIRE PART: 42 U.S.C. 2165; 42 U.S.C. 2201; 42 U.S.C. 5814-5815; 42 U.S.C. 7101 et seq.; 50 U.S.C. 2401 et seq.; E.O. 10450, 3 CFR 1949-1953 Comp., p. 936, as amended; E.O. 10865, 3 CFR 1959-1963 Comp., p. 398, as amended; 3 CFR Chap. IV. ${ }^{13}$

Because Executive Order No. 10450 is listed as part of the authority for the HRP, and the National Driver Register Act now authorizes disclosure to "an individual who is being investigated for Federal employment under authority of Executive Order No. 10450," ${ }^{14}$ it is clear that Federal employees in the HRP can access, or consent to DOE accessing, the NDR for their records.

Whether contractor employees in the HRP can access or consent to DOE accessing their NDR records is less clear. The ambiguity is caused by the fact that the authority for the HRP regulations does not include Executive Order 12968, which is specifically listed as a sufficient basis for requesting and receiving information from the NDR. There are three arguments that can be made in an effort to conclude that the HRP is an implementation of Executive Order 12968 even if it is not listed as a basis of authority for the HRP regulation. These arguments follow.

\footnotetext{
${ }^{11} \mathrm{Id}$.

12 See 67 Fed. Reg. 3213 (Jan. 23, 2004).

1310 CFR S712.1 (2006).

1449 U.S.C. \$30305(b)(9) (2006). (Emphasis added)
} 


\section{A. "Operation of law" argument}

Executive Order 12968 was issued in response to a statute that required the President to "establish procedures to govern access to classified information which shall be binding upon all departments, agencies, and offices of the executive branch of Government."15 The President's response was Executive Order 12968 which, as required by Congress, applies to all federal departments and agencies. This includes DOE. Thus, by operation of law, all of the security programs of DOE related to access to classified information are implementations of Executive Order 12968. The fact that the HRP regulation does not identify or list that executive order as a basis of authority does not change the legal conclusion that it is based on that executive order. Congress has spoken clearly on the point that all departments, including DOE, must base their regulations regarding access to classified information on Executive Order 12968, and that requirement is binding on DOE. ${ }^{16}$ Failure to identify Executive Order 12968 as authority for the HRP regulation is an administrative oversight, not a legal flaw.

Executive Order 12968 specifically includes employees of contractors as part of the set of persons to which the access regulations apply. ${ }^{17}$ Thus, any employee of a DOE contractor in the HRP may request and receive information from the NDR, and such an employee can consent to DOE doing so.

\section{B. “Incorporation” argument}

As noted above, the HRP regulation lists Executive Order 10865 as a source of authority. Executive Order 12968 specifically includes a provision regarding Executive Order 10865, which states, in part:

To the extent that this order is inconsistent with any provision of any prior Executive order, this order shall control, except that this order shall not diminish or

\footnotetext{
1550 U.S.C. $\$ 435($ a) (2006).

${ }^{16}$ Chevron U.S.A. v. Natural Resources Defense Council, 467 U.S. 837, 842-843 (1984): "First, always, is the question whether Congress has directly spoken to the precise question at issue. If the intent of Congress is clear, that is the end of the matter; for the court, as well as the agency, must give effect to the unambiguously expressed intent of Congress." (emphasis added).

${ }^{17}$ Executive Order 12968, \$1.1(e).
} 
otherwise affect the requirements of $\ldots$ the denial and revocation procedures provided to individuals covered by Executive Order No. $10865 \ldots . .^{18}$

This provision of Executive Order 12968 can be interpreted as incorporating Executive Order 10865 into Executive Order 12968; that is, making the old executive order a part of the new one. From this it follows that, because the HRP regulation specifically identifies Executive Order 10865 as a source of authority, it implicitly includes the overarching executive order as well. Thus, because Executive Order 12968 specifically includes employees of contractors as part of the set of persons to which the access regulations apply, ${ }^{19}$ any employee of a DOE contractor in the HRP may request and receive information from the NDR, and such an employee can consent to DOE doing so.

This incorporation argument is strengthened by the fact that a prerequisite for an individual having an HRP certification is that he or she must have access authorization under $10 \mathrm{CFR}$ Part $710 .{ }^{20}$ As discussed below in Section IV, this access authorization regulation lists Executive Order 10865 as a source of authority; thus, there is a double incorporation of Executive Order 12968.

\section{C. “Combination” argument}

The strongest argument that the HRP is an implementation of Executive Order 12968 comes from combining the two previous arguments. First, Congress required the President to issue an executive order governing access to classified information by all persons. Second, the President complied by issuing Executive Order 12968 which specifically acknowledged Executive Order 10865. The reference is the method chosen by the President to carry out the obligation established by Congress. Thus, the reference to Executive Order 12968 in the National Driver Registry Act as a sufficient basis for requesting and receiving information from the $\mathrm{NDR}^{21}$ is satisfied by the listing of Executive Order 10865 as a source of authority for the regulation creating the HRP.

\footnotetext{
${ }^{18}$ Executive Order 12968, \$7.1(c).

${ }^{19}$ Executive Order 12968, \$1.1(e).

2010 CFR \$712.11 (2006). This access authorization commonly is referred to as a Q Clearance.

2149 U.S.C. $\$ 30305(b)(9)(2006)$.
} 


\section{Using the NDR in the Access Authorization Program: A Brief Overview}

To determine whether the NDR can be used by DOE in making access authorization decisions, one must analyze the applicable regulation, 10 CFR Part 710 (2006).

This regulation lists Executive Order 10450 as a source of authority. Because the National Driver Register Act now authorizes disclosure to "an individual who is being investigated for Federal employment under authority of Executive Order 10450"22 it is clear that Federal employees being considered for access authorization can access or consent to DOE accessing the NDR for their records.

The DOE access authorization regulation does not explicitly list Executive Order 12968 as a source of authority. Thus, the conclusion that DOE security officials can have access to contractor employees' NDR records must be based on an interpretation of the National Driver Register Act, Executive Order 12968, and 50 U.S.C. \$435(a). Each of the three arguments given previously regarding the availability of NDR records to HRP officials applies regarding access by security officials.

The first argument is clearly applicable because the law mandates "procedures to afford access to classified information... binding upon all departments."23 DOE's access authorization is just such a program.

The second argument is clearly applicable because the security regulation specifically lists Executive Order 10865 as a source of authority. Because the first and second arguments apply, this combination does also.

\section{HRP: Conclusion and Suggestion}

This report has given three arguments that support the position that the HRP can include a procedure for obtaining and considering information from the NDR. To remove the risk that the HRP regulation must explicitly list Executive Order 12968 as a source of authority before it can access the NDR, DOE could issue a regulation doing so.

\footnotetext{
2249 U.S.C. $\$ 30305(b)(9)$ (2006). (Emphasis added)

${ }^{23} 50$ U.S.C. $\$ 435$ (a) (2006).
} 
The use of this database could be as useful to DOE in the HRP as it has been to the Federal Aviation Administration. ${ }^{24}$ However, problems with its timeliness and completeness have been reported. $^{25}$ In addition to using the NDR in individual cases, HRP personnel might find it useful for answering questions about how the system of reporting arrests is functioning. ${ }^{26}$ These same conclusions apply for the access authorization program.

\footnotetext{
${ }^{24}$ See, e.g., Ramapraksh v. Federal Aviation Administration, 346 F.3d 1121 (D.C. Cir. 2003) (describing how the FAA utilizes the NDR in individual cases).

${ }^{25}$ See Robyn D. Robertson and Herb M. Simpson, Judicial Report on the Adjudication and Sanctioning of Hard-Core Drinking Drivers, 40 Court Review 8, (2003); "Currently, almost half of judges (44\%) rely upon the National Driver Register (NDR) as an effective tool for identifying prior convictions. The information contained in this database is derived from reports forwarded from the licensing agencies of every state. However, the ability of state repositories to maintain accurate records is largely dependent on their ability to collect and enter pertinent information from multiple agencies (e.g., police, courts) in real time. In some jurisdictions, it may take more than six months for arrests and convictions to be recorded. In other jurisdictions, convictions may be omitted entirely. Although the NDR database expedites the record-searching process, judges support the continued effort to improve the timeliness and quality of its information."

${ }^{26}$ For a description of how the NDR can be used for statistical studies, see Brett D. Venhuizen, Alcobol Offenses and the Reporting Requirements of 14 C.F.R. 61.15, 78 N. Dak. L. Rev. 741 (2002).
} 